\title{
A Palladium-Catalyzed Oxa-(4+4)-Cycloaddition Strategy Towards Oxazocine Scaffolds
}

\author{
Anaïs Scuiller ${ }^{\mathrm{a}}$ \\ Xueyang Liu ${ }^{\mathbf{a}}$ \\ Marie Cordier ${ }^{b, 1}$ \\ Julian Garrec*c \\ Alexis Archambeau*a (iD) \\ Laboratoire de Synthèse Organique, UMR 7652, Ecole Polytechnique, \\ ENSTA Paris, CNRS, IP Paris, 91128 Palaiseau, France \\ alexis.archambeau@polytechnique.edu \\ Laboratoire de Chimie Moléculaire, UMR 9168, Ecole Polytechnique, \\ CNRS, IP Paris, 91128 Palaiseau, France \\ Unité Chimie et Procédés, ENSTA Paris, IP Paris, 91120 Palaiseau, \\ France \\ julian.garrec@ensta-paris.fr
}
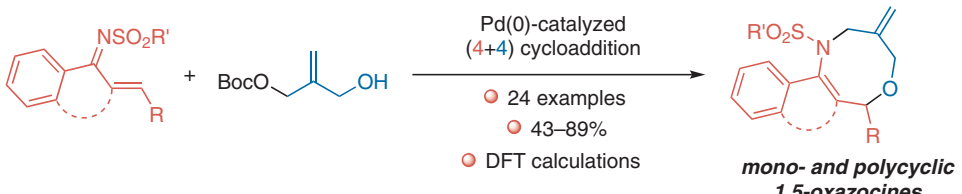

Received: 16.03 .2021

Accepted after revision: 17.04.2021

Published online: 19.05 .2021

DOI: 10.1055/s-0040-1706038; Art ID: st-2021-v0101-I

Abstract A Pd-catalyzed oxa-(4+4)-cycloaddition between 1-azadienes and (2-hydroxymethyl)allyl carbonates is described. Aurone-derived azadienes furnished polycyclic 1,5-oxazocines in good yields. Interestingly, linear azadienes have also been involved and yielded monocyclic heterocycles with complete regioselectivity. DFT calculations were carried out to gain insight on this observation.

Key words cycloaddition, catalysis, heterocycles, medium-sized rings, oxazocines, azadienes

Medium-sized heterocycles are constituents of several biologically active natural products and pharmaceuticals and were successfully incorporated in several drug leads ${ }^{2}$ as their structure confers them with favorable pharmacokinetic properties. ${ }^{3}$ However, their tedious preparation ${ }^{4-6}$ hampers a more thorough investigation of these scaffolds in medicinal chemistry and the development of new methods for their synthesis is of foremost importance (Figure 1).

Cycloadditions of 1,n-dipoles have recently emerged as an efficient tool towards medium-sized rings. These transformations involve at least one stable partner and auronederived azadienes have been exploited in numerous $(n+4)$ cycloadditions as an electrophilic 1,4-dipole (Scheme 1a). ${ }^{7-}$ 12 Several catalyzed cycloadditions relying on $\pi$-allyl $\mathrm{Pd}^{\mathrm{II}}$ chemistry employed these electrophiles and Trost described the reactivity of a palladium-trimethylenemethane derivative in a $(3+4)$ cycloaddition. ${ }^{9 \mathrm{c}}$ Zhao reported the formation of medium-sized nine- and ten-membered heterocycles using vinyl carbonate ${ }^{11 a}$ and vinyl oxetanes ${ }^{12}$ as $1,5-$ and 1,6-dipoles, respectively (Scheme 1b). Aurone-derived azadienes can also behave as an electrophilic 1,2-dipole (via

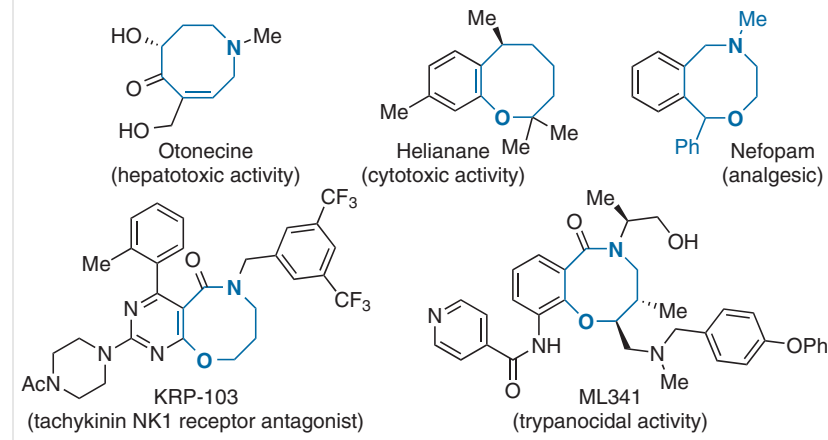

Figure 1 Examples of oxygenated and nitrogenated eight-membered rings with biological activities

the $\mathrm{C}=\mathrm{C}$ or the $\mathrm{C}=\mathrm{O}$ bond) and spiro compounds have also been prepared via $(1+2)^{13}$ and $(3+2)$ cycloadditions. ${ }^{14}$

Linear azadienes, derived from chalcones, display a different reactivity. While they also operate as a 1,4-electrophilic dipole in several $(1+4)^{15}$ and in a wide variety of $(2+4)$ cycloadditions (hetero-Diels-Alder), ${ }^{16}$ they generally act as an activated alkene (1,2-dipole with the $\mathrm{C}=\mathrm{C}$ bond) when opposed to nucleophilic $1, n$-dipole $(n \geq 3)$ to afford the corresponding $(n+2)$ cycloadducts. ${ }^{17-19}$ (Scheme 1a). Our group recently reported a Pd-catalyzed $(5+4)$ cycloaddition between azadienes and vinylcyclopropanes highlighting the difficulty to involve linear 1 -azadienes with complete regiocontrol as $(3+2)$ side cycloadducts were also obtained (Scheme 1b). ${ }^{11 \mathrm{c}}$ In this context, we became interested in nucleophilic oxa-1,4-dipoles generated in situ from (2-hydroxymethyl) allyl carbonates and a $\mathrm{Pd}^{0}$ catalyst. ${ }^{20}$ Herein we report a regioselective palladium-catalyzed (4+4)-cycloaddition process involving these intermediates and cy- 


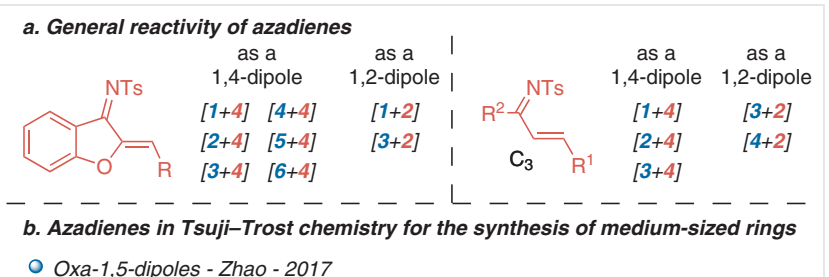

5-dipoles - Zhao - 2017

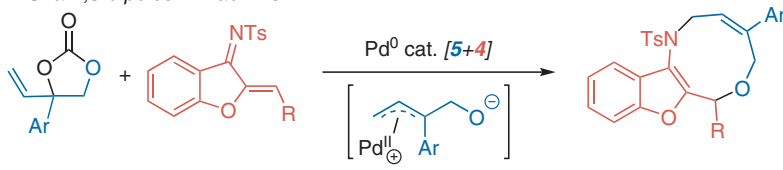

- Previous work from our group - 2021

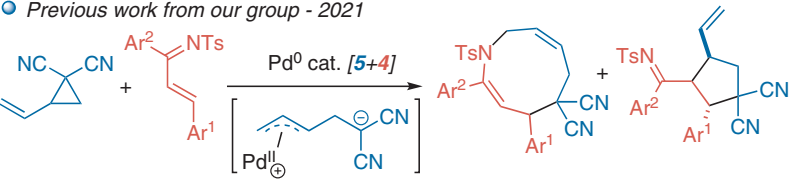

c. This work: Formation of 1,5-oxazocines
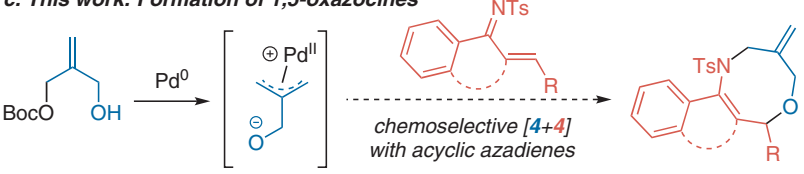

Scheme 1 General reactivity of acyclic and aurone-derived azadienes
Table 1 Optimization of the Reaction Conditions ${ }^{\mathrm{a}}$

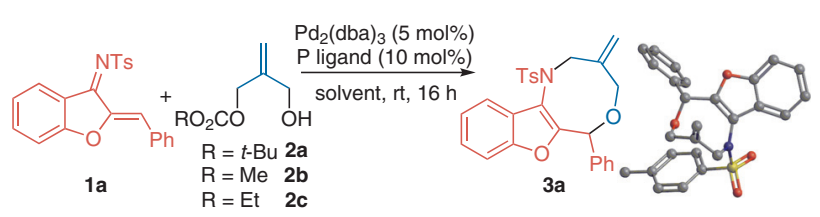

\begin{tabular}{ccllll}
\hline Entry & Substrate & $\mathrm{R}$ & Ligand & Solvent & Yield (\%) \\
\hline 1 & $\mathbf{2 a}$ & $t$-Bu & dppe & toluene & 81 \\
2 & $\mathbf{2 b}$ & $\mathrm{Me}$ & dppe & toluene & 77 \\
3 & $\mathbf{2 c}$ & $\mathrm{Et}$ & dppe & toluene & 74 \\
4 & $\mathbf{2 a}$ & $t-\mathrm{Bu}$ & $\mathrm{PPh}_{3}$ & toluene & - \\
5 & $\mathbf{2 a}$ & $t-\mathrm{Bu}$ & XantPhos & toluene & 12 \\
6 & $\mathbf{2 a}$ & $t-\mathrm{Bu}$ & dppbz & toluene & 80 \\
7 & $\mathbf{2 a}$ & $t-\mathrm{Bu}$ & dppe & benzene & $92(86)$ \\
8 & $\mathbf{2 a}$ & $t-\mathrm{Bu}$ & dppe & $\mathrm{CH}_{2} \mathrm{Cl}$ & 25 \\
9 & $\mathbf{2 a}$ & $t-\mathrm{Bu}$ & dppe & $\mathrm{THF}_{2}$ & 61 \\
10 & $\mathbf{2 a}$ & $t-\mathrm{Bu}$ & dppe & - & - \\
\hline
\end{tabular}

a Reaction conditions: $1 \mathbf{a}(0.1 \mathrm{mmol}), \mathbf{2 a}(0.15 \mathrm{mmol}), \mathrm{Pd}_{2}(\mathrm{dba})_{3}(0.005$ $\mathrm{mmol})$, ligand $(0.01 \mathrm{mmol})$ in solvent $(1 \mathrm{~mL})$ for $16 \mathrm{~h}$ at room temperature. ${ }^{\mathrm{b}}$ NMR yields; isolated yield in parentheses.

formation as cycloadduct $\mathbf{3 b}(86 \%)$ and $\mathbf{3 c}(72 \%)$ were isolated in good yields. The behavior of several aurone-derived 1azadienes with different aryl group at the $C_{4}$ position was then interrogated. Oxazocines bearing electron-rich $p$-methoxyphenyl (3d) and 3,4-dimethoxphenyl (3e) rings were generated smoothly under the previously optimized set of conditions. The steric hindrance occasioned by an 0 -methyl or a 1-naphthyl group did not alter the cycloaddition process which afforded smoothly eight-membered rings $\mathbf{3 f}$ and $3 \mathrm{~g}$, respectively. Electron-deficient aryl groups are also tolerated: azadiene $\mathbf{1 h}$ derived from $m$-cyanobenzaldehyde proved to be a suitable substrate. However, the introduction of the strong inductive electron-withdrawing $p$-trifluoromethyl group came with a slight yield decrease as our catalytic process furnished $\mathbf{3 i}$ (42\%) in moderate yield. The presence of an aromatic halogen atom was also examined and oxazocine $3 \mathbf{j}$ bearing an $\boldsymbol{o}$-chlorine substituent, suitable for further functionalization, was prepared in good yield (85\%). Gratifyingly, a heteroaromatic moiety such as 2-thiophenyl was also introduced and the $(4+4)$ cycloaddition proceeded smoothly to furnish oxazocine 3k. We tackled the challenge of introducing an alkyl group at the $\mathrm{C}_{4}$ position. While this study was limited by the instability of the corresponding starting material, we were delighted to prepare oxazocine 31 bearing a tert-butyl group in $72 \%$ yield. Finally, the sulfonamide moiety was also modified and oxazocine $\mathbf{3 m}$ (80\%) with a 2-nitrosulfonamide was efficiently generated (Scheme 2). 


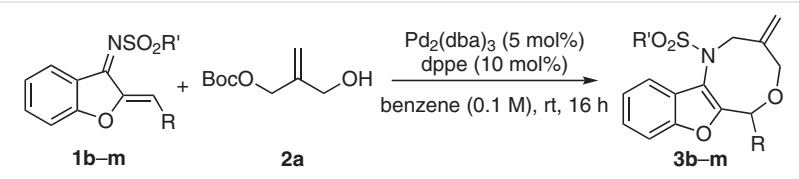

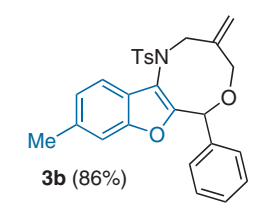

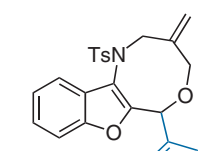

3e $(59 \%)$
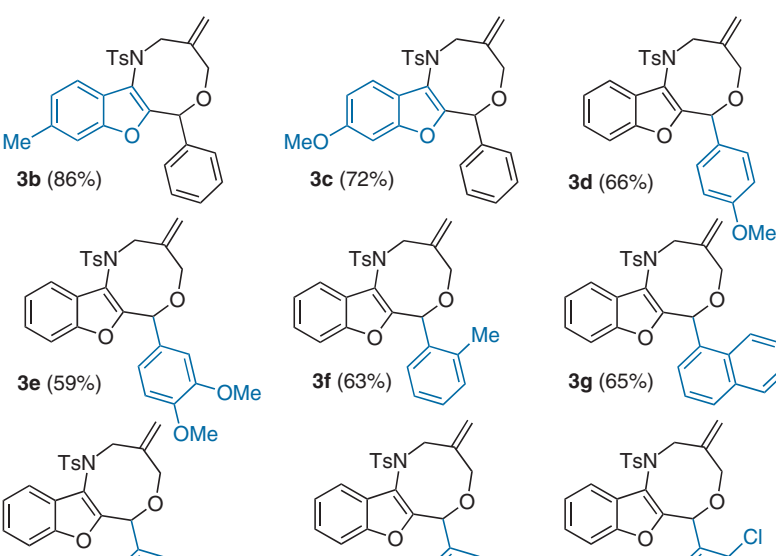

$3 \mathbf{h}(63 \%) \longrightarrow \mathrm{CN}$<smiles>C=C1COC(c2cccs2)c2oc3ccccc3c2[Al]C1</smiles>
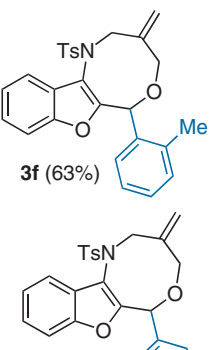

$3 \mathbf{i}(42 \%)$

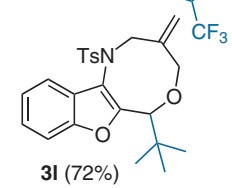

$3 \mathbf{g}(65 \%)$
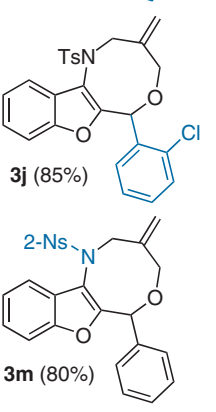

Scheme 2 Formation of benzofuran-fused oxazocines

The reactivity of chromanone-derived azadiene $\mathbf{1 n}$ was then questioned. It was here necessary to work at higher temperature (toluene, $50{ }^{\circ} \mathrm{C}$ ) to isolate the expected polycyclic oxazocine $3 n$ (49\%). A putative (4+4) cycloaddition does not come with a concurrent aromatization, unlike the previous case of aurone-derived azadienes (Scheme 3 ).

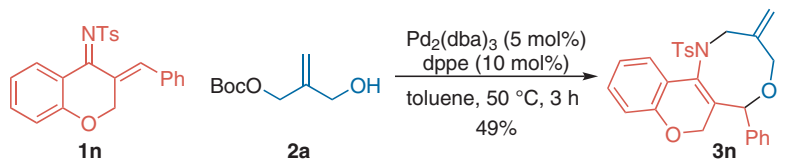

Scheme 3 General reactivity of acyclic and aurone-derived azadienes

This encouraging result prompted us to investigate the behavior of acyclic 1-azadienes derived from chalcones under our (4+4)-cycloaddition conditions. Azadiene 4a was prepared from benzylideneacetophenone and selected as our test substrate. An elevation of the temperature $\left(50{ }^{\circ} \mathrm{C}\right.$, toluene) was also required to achieve a smooth (4+4) cycloaddition towards the corresponding monocyclic 1,5-oxazocine 5a (77\%), whose structure has been confirmed by XRD analysis. ${ }^{22}$ The azadiene $\mathbf{4 b}$, bearing a $p$-nitrobenzene sulfonamide moiety, was a suitable substrate under the same reaction conditions and led to the corresponding medium-sized heterocycle $\mathbf{5 b}(61 \%)$. The ease of preparation of acyclic 1 -azadienes bearing different aryl group at $C_{2}$ and $C_{4}$ allowed us to further review the scope of this monocyclic oxazocine synthesis. Under the previously described reaction conditions, azadienes $\mathbf{4 c}$ and $\mathbf{4 d}$, bearing electron-donating substituents (3-OMe; $3,4-\mathrm{OCH}_{2} \mathrm{O}$ ) on the $\mathrm{Ar}^{1}$ group, were readily converted into the expected cycloadducts. An electron-rich heteroaromatic 2-furane was well-tolerated and our method furnished oxazocine $\mathbf{5 e}(89 \%)$ in very good yield. Electron-withdrawing substituent $\left(p-\mathrm{F}, p-\mathrm{CF}_{3}\right)$ on $\mathrm{Ar}^{1}$ did not alter the reaction outcome as oxazocines $\mathbf{5 f}(63 \%)$ and $\mathbf{5 g}(63 \%)$ were obtained from the corresponding azadienes. Various substitutions are also tolerated on the $\mathrm{Ar}^{2}$ ring as $\mathbf{1 , 5}$-oxazocines $\mathbf{5 h}, \mathbf{5 i}$, and $\mathbf{5 j}$ bearing an electron-donating $p$-methyl, a 2-naphthyl, or an electron-withdrawing $p$-fluoro substituent, respectively, were generated in moderate to good yields (Scheme 4).

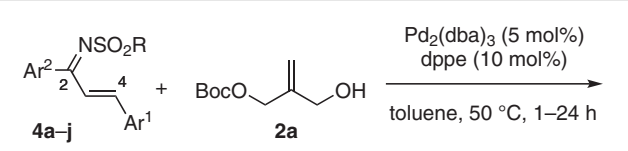
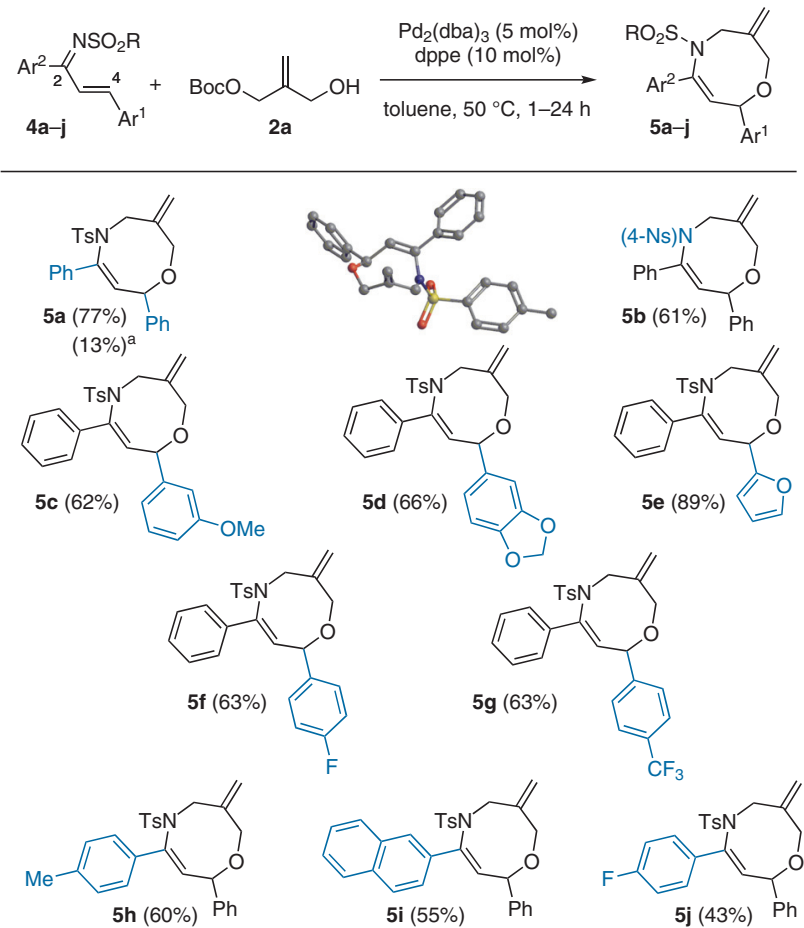

Scheme 4 Formation of monocyclic oxazocines. ${ }^{a}$ Reaction run at rt.

A mechanism was proposed to illustrate this $(4+4)$ process. After complexation (not shown) with the alkene moiety of $\mathbf{2 a}$ followed by an oxidative addition to generate $\mathrm{Pd}^{\mathrm{II}}$ $\pi$-allyl complex $\mathbf{A}$, the in situ generated tert-butanolate can deprotonate the alcohol moiety and lead to the 1,4-dipole B. An oxa-Michael addition into azadiene 4a then generates the key $\mathrm{Pd}^{\mathrm{II}}-\pi$-allyl complex intermediate $\mathbf{C}$. The eightmembered ring $\mathbf{5 a}$ could result from pathway (a) after addition of the sulfonamide anion to the $\pi$-allyl-PdII. As carbon $\mathrm{C}_{3}$ is not highly congested, one could imagine an alternative pathway (b) involving a (4+2) cycloaddition leading to tetrahydropyran 6. While this product could never be observed, a fast aza-Claisen rearrangement could also lead to 
oxazocine $\mathbf{5 a}$ but this reaction pathway has been ruled as DFT calculations showed a very high energy barrier of about $45 \mathrm{kcal} / \mathrm{mol}$ (Scheme 5$).^{23}$

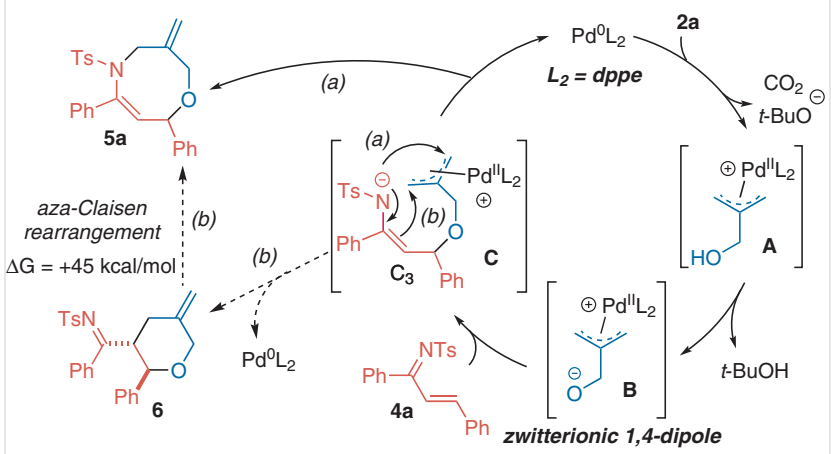

Scheme 5 Proposed mechanism

In order to shed some light on the observed, regioselectivity favoring a $(4+4)$ cycloaddition, we explored the microscopic details of the reaction using density functional theory (DFT) calculations. We identified three reactant conformers, namely $\mathrm{R}_{a}, \mathrm{R}_{b}$ and $\mathrm{R}_{c}$, which are in thermal equilibrium (represented with dashed line in Figure 2). It turns out that the $(4+4)$ cycloaddition is virtually barrierless $\left(G_{\mathrm{TSa}}=\right.$ ca. $\left.G_{\mathrm{Ra}}\right)$. Taking a closer look at the structures of $\mathrm{R}_{a}$ and $\mathrm{TS}_{a}$, we notice that they are very similar, which, by virtue of the Hammond principle, provides an explanation for the fact that the two structures have almost the same free energy: reaching the transition state requires a minimal amount of structural reorganization that comes together with only a small increase in cycle tension. It is also worth stressing that there is a stabilizing electrostatic attraction between the negatively charged nitrogen atom and the carbocation in $\mathrm{R}_{a}$ which is exacerbated by the low dielectric constant of the solvent. A competitive $(4+2)$ pathway (b) could occur from reactant conformer $\mathrm{R}_{b}\left(G_{\mathrm{R} b}=c a\right.$. $\left.G_{\mathrm{R} a}\right)$. However, its chemical step is associated with a higher activation barrier $\left(G_{\mathrm{TSb}}-G_{\mathrm{R} b}=\right.$ ca. $\left.10 \mathrm{kcal} / \mathrm{mol}\right)$. This is due to the boat conformation of $\mathrm{TS}_{b}$, which typically requires more energy to be formed from the reactant. A chair transition state $\mathrm{TS}_{c}$ can be reached following another $(4+2)$ pathway (c) with a much lower free-energy barrier $\left(G_{\mathrm{TSc}}-G_{\mathrm{Rc}}=\mathrm{ca} .3 \mathrm{kcal} / \mathrm{mol}\right)$. However, the overall free-energy landscape of this pathway is much higher than the two others due to the high free energy of $\mathrm{R}_{c}$ with respect to $\mathrm{R}_{a}$ and $\mathrm{R}_{b}$. As highlighted in the gray box, this is due to a strong steric conflict between the sulfonyl group and the oxygen atom to which the carbocation is attached in $\mathrm{R}_{c}$. Finally, the free energy of the eight-membered ring is only slightly higher than that of the most stable six-membered ring that we obtained $\left(G_{P a}-G_{P b}=\right.$ ca. 4 $\mathrm{kcal} / \mathrm{mol}$ ). The overall picture that emerges from our calculations is that the system gets kinetically trapped into the free energy basin corresponding to $\mathrm{P}_{a}$ (Figure 2).

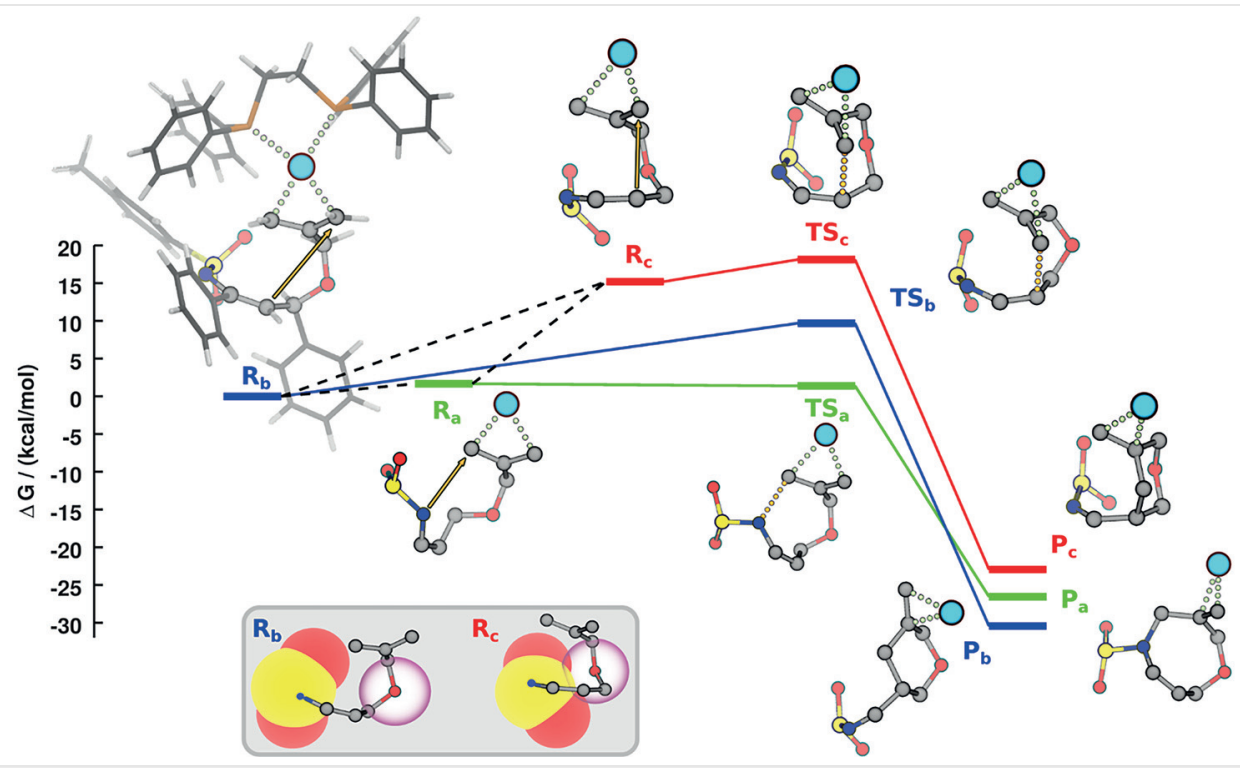

Figure 2 Free energy profiles of the cyclization reactions following a (4+4)-cycloaddition mechanism (pathway (a) in green), a (4+2)-cycloaddition mechanism involving a boat conformation at the TS (pathway (b) in blue) and a (4+2)-cycloaddition mechanism involving a chair conformation at the TS (pathway (c) in red). Each free energy is defined relative to the most stable conformer of the reactant, namely $\mathrm{R}_{b}$. Conformational transitions and chemical steps are represented with dashed and plain lines, respectively. For the sake of clarity, the full molecular structure is represented only for $R_{b}$. For all the other stationary states, only key backbone atoms involved in the cyclization process are represented (hydrogen atoms are removed from the representation too). More detailed representations of the same structures are provided in the Supporting Information. For each reaction pathway, the nucleophilic attack is represented with an orange arrow and the corresponding forming bond at the TS is depicted with orange dots. The lower gray box provides additional representations of the reactive backbone of $R_{b}$ and $R_{c}$ in order to emphasize the steric conflict between the sulfonyl group (plain spheres) and the endocyclic oxygen atom (transparent magenta sphere). 
In this study, we have disclosed an original pathway to benzofuran-fused $[1,5]$-oxazocines via a palladium-catalyzed (4+4) cycloaddition with (2-hydroxymethyl)allyl carbonates. ${ }^{24}$ Acyclic azadienes have also been involved in this process and monocyclic eight-membered rings were obtained with complete regioselectivity and DFT calculations were carried out to rationalize this peculiar finding.

\section{Conflict of Interest}

The authors declare no conflict of interest.

\section{Funding Information}

This work was supported by the Agence Nationale de la Recherche (JCJC grant CycloSyn, ANR-18-CE07-0008). X.L. thanks the Agence Nationale de la Recherche for a M2 grant. A.S. thanks Labex CHARMMMAT (ANR-11-LABX-0039) for a M2 grant and the Agence Nationale de la Recherche for a PhD fellowship.

\section{Supporting Information}

Supporting information for this article is available online at https://doi.org/10.1055/s-0040-1706038.

\section{References and Notes}

(1) Current address: Univ Rennes, CNRS ISCR-UMR 6226, 35000 Rennes, France.

(2) (a) Bodireddy, M. R.; Krishnaiah, K.; Babu, P. K.; Bitra, C.; Gajula, M. R.; Kumar, P. Org. Process Res. Dev. 2017, 21, 1745. (b) Audouze, K.; Nielsen, E. Ø.; Peters, D. J. Med. Chem. 2004, 47, 3089. (c) Dandapani, S.; Germain, A. R.; Jewett, I.; Le Quement, S.; Marie, J.-C.; Muncipinto, G.; Duvall, J. R.; Carmody, L. C.; Perez, J. R.; Engel, J. C.; Gut, J.; Kellar, D.; Siqueira-Neto, J. L.; McKerrow, J. H.; Kaiser, M.; Rodriguez, A.; Palmer, M. A.; Foley, M.; Schreiber, S. L.; Munoz, B. ACS Med. Chem. Lett. 2014, 5, 149. (d) Tanioka, A.; Deguchi, T. Drug. Res. 2017, 67, 302.

(3) (a) Khan, A. R.; Parrish, J. C.; Fraser, M. E.; Smith, W. W.; Bartlett, P. A.; James, M. N. G. Biochemistry 1998, 37, 16839. (b) Taylor, R. D.; Maccoss, M.; Lawson, A. D. G. J. Med. Chem. 2014, 57, 5845. (c) Rezai, T.; Yu, B.; Millhauser, G. L.; Jacobson, M. P.; Lokey, R. S. J. Am. Chem. Soc. 2006, 128, 2510. (d) Kwon, Y.-U.; Kodadek, T. Chem. Biol. 2007, 14, 671.

(4) For books on medium-sized-ring synthesis, see: (a) Newkome, G. R. Eight-Membered and Larger Rings, In Progress in Heterocyclic Chemistry; Suschitzky, H.; Scriven, E. F. V., Ed.; Elsevier: Amsterdam, 1991, 319. (b) Quirke, J. M. E. Eight-Membered and Larger Rings Systems, In Heterocyclic Chemistry; Suschitzky, H., Ed.; Royal Society of Chemistry: London, 1986, 455.

(5) For reviews on medium-sized rings, see: (a) Molander, G. A. Acc. Chem. Res. 1998, 31, 603. (b) Yet, L. Chem. Rev. 2000, 100, 2963. (c) Maier, M. E. Angew. Chem. Int. Ed. 2000, 39, 2073. (d) Roxburgh, C. J. Tetrahedron 1993, 49, 10749. (e) Donald, J. R.; Unsworth, W. P. Chem. Eur. J. 2017, 23, 8780. (f) Clarke, A. K.; Unsworth, W. P. Chem. Sci. 2020, 11, 2876. (g) Choury, M.; Basilio Lopes, A.; Blond, G.; Gulea, M. Molecules 2020, 25, 3147.

(6) (a) Illuminati, G.; Mandolini, L. Acc. Chem. Res. 1981, 14, 95. (b) Galli, C.; Mandolini, L. Eur. J. Org. Chem. 2000, 3117.
(7) For a (1+4) cycloaddition, see: Wang, C.-S.; Li, T.-Z.; Cheng, Y.-C.; Zhou, J.; Mei, G.-J.; Shi, F.J. Org. Chem. 2019, 84, 3214.

(8) For $(2+4)$ cycloadditions, see: (a) Rong, Z.-Q.; Wang, M.; Chow, C. H. E.; Zhao, Y. Chem. Eur. J. 2016, 22, 9483. (b) Gu, Z.; Wu, B.; Jiang, G.-F.; Zhou, Y.-G. Chin. J. Chem. 2018, 36, 1130. (c) Fan, T.; Zhang, Z.-J.; Zhang, Y.-C.; Song, J. Org. Lett. 2019, 21, 7897. (d) Li, X.; Yan, J.; Qin, J.; Lin, S.; Chen, W.; Zhan, R.; Huang, H. J. Org. Chem. 2019, 84, 8035. (e) Marques, A.-S.; Duhail, T.; Marrot, J.; Chataigner, I.; Coeffard, V.; Vincent, G.; Moreau, X. Angew. Chem. Int. Ed. 2019, 58, 9969.

(9) For (3+4) cycloadditions, see: (a) Chen, J.; Jia, P.; Huang, Y. Org. Lett. 2018, 20, 6715. (b) Gao, Z.-H.; Chen, K.-Q.; Zhang, Y.; Kong, L.-M.; Li, Y.; Ye, S. J. Org. Chem. 2018, 83, 15225. (c) Trost, B. M.; Zuo, Z. Angew. Chem. Int. Ed. 2020, 59, 1243. (d) Kumari, P.; Liu, W.; Wang, C.-J.; Dai, J.; Wang, M.-X.; Yang, Q.-Q.; Deng, Y.-H.; Shao, Z. Chin. J. Chem. 2020, 38, 151. (e) Liu, Y.-Z.; Wang, Z.; Huang, Z.; Zheng, X.; Yang, W.-L.; Deng, W.-P. Angew. Chem. Int. Ed. 2020, 59, 1238. (f) Yan, R.-J.; Liu, B.-X.; Xiao, B.-X.; Du, W.; Chen, Y.-C. Org. Lett. 2020, 22, 4240.

(10) For (4+4) cycloadditions, see: (a) Ni, H.; Tang, X.; Zheng, W.; Yao, W.; Ullah, N.; Lu, Y. Angew. Chem. Int. Ed. 2017, 56, 14222. (b) Jiang, B.; Du, W.; Chen, Y.-C. Chem. Commun. 2020, 56, 7257. (c) Li, Q.; Pan, R.; Wang, M.; Yao, H.; Lin, A. Org. Lett. 2021, 23, 2292.

(11) For (5+4) cycloadditions, see: (a) Yang, L.-C.; Rong, Z.-Q.; Wang, Y.-N.; Tan, Z. Y.; Wang, M.; Zhao, Y. Angew. Chem. Int. Ed. 2017, 56, 2927. (b) Rong, Z.-Q.; Yang, L.-C.; Liu, S.; Yu, Z.; Wang, Y.-N.; Tan, Z. Y.; Huang, R.-Z.; Lan, Y.; Zhao, Y. J. Am. Chem. Soc. 2017, 139, 15304. (c) Scuiller, A.; Karnat, A.; Casaretto, N.; Archambeau, A. Org. Lett. 2021, 23, 2332.

(12) For a (6+4) cycloaddition, see: Wang, Y.-N.; Yang, L.-C.; Rong, Z.Q.; Liu, T.-L.; Liu, R.; Zhao, Y. Angew. Chem. Int. Ed. 2018, 57, 1596.

(13) Fang, Q.-Y.; Yi, M.-H.; Wu, X.-X.; Zhao, L.-M. Org. Lett. 2020, 22, 5266.

(14) (a) Verma, K.; Taily, I. M.; Banerjee, P. Org. Biomol. Chem. 2019, 17, 8149. (b) Trost, B. M.; Zuo, Z. Angew. Chem. Int. Ed. 2021, 60, 5806.

(15) (a) Tian, J.; Zhou, R.; Sun, H.; Song, H.; He, Z. J. Org. Chem. 2011, 76, 2374. (b) Yang, M.; Wang, T.; Cao, S.; He, Z. Chem. Commun. 2014, 50, 13506. (c) Zheng, P.-F.; Ouyang, Q.; Niu, S.-L.; Shuai, L.; Yuan, Y.; Jiang, K.; Liu, T.-Y.; Chen, Y.-C. J. Am. Chem. Soc. 2015, 137, 9390. (d) Li, H.; Luo, J.; Li, B.; Yi, X.; He, Z. Org. Lett. 2017, 19, 5637. (e) Wang, L.; Li, S.; Blümel, M.; Puttreddy, R.; Peuronen, A.; Rissanen, K.; Enders, D. Angew. Chem. Int. Ed. 2017, 56, 8516.

(16) (a) Boger, D. L.; Kasper, A. M. J. Am. Chem. Soc. 1989, 111, 1517. (b) Esquivias, J.; Arrayás, R. G.; Carretero, J. C. J. Am. Chem. Soc. 2007, 129, 1480. (c) Han, B.; Li, J.-L.; Ma, C.; Zhang, S.-J.; Chen, Y.-C. Angew. Chem. Int. Ed. 2008, 47, 9971. (d) Jiang, X.; Shi, X.; Wang, S.; Sun, T.; Cao, Y.; Wang, R. Angew. Chem. Int. Ed. 2012, 51, 2084. (e) Stark, D. G.; Morrill, L. C.; Yeh, P.-P.; Slawin, A. M. Z.; O'Riordan, T. J. C.; Smith, A. D. Angew. Chem. Int. Ed. 2013, 52, 11642.

(17) (a) Verma, K.; Banerjee, P. Adv. Synth. Catal. 2017, 359, 3848. (b) Bai, D.; Yu, Y.; Guo, H.; Chang, J.; Li, X. Angew. Chem. Int. Ed. 2020, 59, 2740.

(18) Burlow, N. P.; Howard, S. Y.; Saunders, C. M.; Fettinger, J. C.; Tantillo, D. J.; Shaw, J. T. Org. Lett. 2019, 21, 1046.

(19) For a recent exception, see this $(4+3)$ cycloaddition: Yuan, C.; Zhang, H.; Yuan, M.; Xie, L.; Cao, X. Org. Biomol. Chem. 2020, 18, 1082. 
(20) (a) Gao, R.-D.; Xu, Q.-L.; Zhang, B.; Gu, Y.; Dai, L.-X.; You, S.-L. Chem. Eur.J. 2016, 22, 11601. (b) Yuan, Z.; Pan, R.; Zhang, H.; Liu, L.; Lin, A.; Yao, H. Adv. Synth. Catal. 2017, 359, 4244. (c) Mao, B.; Liu, H.; Yan, Z.; Xu, Y.; Xu, J.; Wang, W.; Wu, Y.; Guo, H. Angew. Chem. Int. Ed. 2020, 59, 11316. (d) Song, X.; Xu, L.; Ni, Q. Org. Biomol. Chem. 2020, 18, 6617. (e) Dai, W.; Li, C.; Liu, Y.; Han, X.; Li, X.; Chen, K.; Liu, H. Org. Chem. Front. 2020, 7, 2612.

(21) CCDC 2040269 contains the supplementary crystallographic data for this paper. The data can be obtained free of charge from The Cambridge Crystallographic Data Centre via www.ccdc.cam.ac.uk/structures

(22) CCDC 2040268 contains the supplementary crystallographic data for this paper. The data can be obtained free of charge from The Cambridge Crystallographic Data Centre via www.ccdc.cam.ac.uk/structures

(23) See the Supporting Information.

(24) Typical Procedure for the Pd-Catalyzed (4+4) Cycloadditions of 2a with 1a (Benzene, rt)

In a screw-cap SVL tube filled with argon, $\mathrm{Pd}_{2}(\mathrm{dba})_{3}(13.7 \mathrm{mg}$,
$0.015 \mathrm{mmol}, 0.05$ equiv) and dppe $(12.0 \mathrm{mg}, 0.03 \mathrm{mmol}, 0.1$ equiv) were added in benzene $(3 \mathrm{~mL}, 0.1 \mathrm{M})$ and stirred for 15 min at rt. Carbonate 2a ( $84.7 \mathrm{mg}, 0.45 \mathrm{mmol}, 1.5$ equiv) and azadiene $1 \mathbf{a}$ (113 $\mathrm{mg}, 0.30 \mathrm{mmol}$ ) were then added, the reaction mixture was stirred at rt for $16 \mathrm{~h}$, filtered over silica, and concentrated under reduced pressure to afford the crude product. The residue was purified by flash column chromatography on silica gel (petroleum ether $/$ EtOAc $=85: 15)$ to afford 3a $(109 \mathrm{mg}$, $81 \%$ ) as a yellow solid; $\mathrm{mp} 46^{\circ} \mathrm{C}$.

IR (neat): 2922, 1597, 1494, 1452, 1384, 1346, 1180, 1157, 1095, 1069, $747 \mathrm{~cm}^{-1} .{ }^{1} \mathrm{H}$ NMR (400 MHz, $\left.\mathrm{CDCl}_{3},-20{ }^{\circ} \mathrm{C}\right): \delta=$ $7.86(\mathrm{~d}, J=8.2 \mathrm{~Hz}, 2 \mathrm{H}), 7.61-7.58(\mathrm{~m}, 1 \mathrm{H}), 7.41-7.12(\mathrm{~m}, 10 \mathrm{H})$, $5.45(\mathrm{~s}, 1 \mathrm{H}), 5.24(\mathrm{~s}, 1 \mathrm{H}), 5.02(\mathrm{~s}, 1 \mathrm{H}), 4.91(\mathrm{~d}, J=13.5 \mathrm{~Hz}, 1 \mathrm{H})$, $4.58(\mathrm{~d}, J=12.6 \mathrm{~Hz}, 1 \mathrm{H}), 4.24(\mathrm{~d}, J=12.6 \mathrm{~Hz}, 1 \mathrm{H}), 4.10(\mathrm{~d}, J=$ $13.5 \mathrm{~Hz}, 1 \mathrm{H}), 2.44(\mathrm{~s}, 3 \mathrm{H}) .{ }^{13} \mathrm{C}$ NMR $\left(101 \mathrm{MHz}, \mathrm{CDCl}_{3},-20{ }^{\circ} \mathrm{C}\right): \delta$ $=154.4,153.0,143.5,139.3,138.1,136.4,129.3$ (2 C), 128.5, 128.4 (2 C), 127.8 (2 C), 127.6 (2 C), 126.6, 124.6, 123.1, 122.7, 120.0, 116.0, 111.3, 79.0, 75.9, 54.7, 21.6. HRMS (ESI $\left.{ }^{+}\right): m / z[M+$ $\mathrm{H}]^{+}$calcd for $\mathrm{C}_{26} \mathrm{H}_{24} \mathrm{NO}_{4} \mathrm{~S}^{+}: 446.1421$; found: 446.1410 . 